\title{
Milk protein fractions moderately extend the duration of satiety compared with carbohydrates independently of their digestive kinetics in overweight subjects
}

\author{
Agnès Marsset-Baglieri ${ }^{1,2}$, Gilles Fromentin ${ }^{1,2}$, Gheorghe Airinei ${ }^{1,2}$, Camilla Pedersen ${ }^{1,2}$, Joëlle Léonil ${ }^{3}$, \\ Julien Piedcoq ${ }^{1,2}$, Didier Rémond ${ }^{4,5}$, Robert Benamouzig ${ }^{1,2}$, Daniel Tomé ${ }^{1,2}$ and Claire Gaudichon ${ }^{1,2 *}$ \\ ${ }^{1}$ INRA, CRNH-IdF, UMR 914 Nutrition Physiology and Ingestive Behavior, F-75005 Paris, France \\ ${ }^{2}$ AgroParisTech, CRNH-IdF, UMR 914 Nutrition Physiology and Ingestive Behavior, 16 rue Claude Bernard, \\ F-75005 Paris, France \\ ${ }^{3}$ INRA, AgroCampus Ouest, UMR STLO, F-35000 Rennes, France \\ ${ }^{4}$ INRA, UMR 1019 Nutrition Humaine, F-63122 Saint Genès, Champanelle, France \\ ${ }^{5}$ Univ Clermont 1, UFR Médecine, UMR 1019 Nutrition Humaine, F-63000 Clermont-Ferrand, France \\ (Submitted 10 December 2013 - Final revision received 19 May 2014 - Accepted 22 May 2014 - First published online 23 June 2014)
}

\begin{abstract}
Digestive kinetics are believed to modulate satiety through the modulation of nutrient delivery. We hypothesised that the duration of satiety could be extended by modulating the kinetics of dietary amino acid delivery in overweight subjects, using snacks containing casein and whey protein. In the present study, eighty-two subjects underwent a first satiety test where they received a control snack containing $60 \mathrm{~g}$ maltodextrin. For the next $5 \mathrm{~d}$, the subjects consumed a liquid protein snack containing $30 \mathrm{~g}$ carbohydrates and $30 \mathrm{~g}$ proteins (casein, whey protein or an equal mix of the two; $n$ 26-28 per group). The subjects then underwent a second satiety test after ingesting the protein snack. The time period elapsing between the snack and request for lunch, food intake at lunch and satiety scores were recorded. A subgroup of twenty-four subjects underwent a digestive and metabolic investigation after ingesting their protein snack. Gastric emptying times were $2 \cdot 5$, 4 and $6 \mathrm{~h}$ for whey protein, mix and casein, respectively, displaying different kinetics of appearance of dietary $\mathrm{N}$ in plasma but without affecting pancreatic and gastrointestinal hormones. Compared with the control snack, proteins extended the duration of satiety $(+17$ min, $P=0.02)$, with no difference between the protein groups. The satiating effect of proteins was greater in subjects who ate their lunch early after the snack (below the median value, i.e. $2 \mathrm{~h}$ ) at the control test $(+32 \mathrm{~min}, P=0 \cdot 001)$. Energy intake at lunch was not modulated by proteins. The satiating effect of proteins is efficient in overweight subjects, especially when the duration of satiety is short, but independently of their digestive and plasma amino acid kinetics.
\end{abstract}

Key words: Casein: Whey protein: Liquid snacks: Satiety: Digestion rates: Mealtime intervals

Dietary proteins are frequently claimed to reduce appetite and then food intake during subsequent meals beyond what can be accounted for by their energy content in humans ${ }^{(1-4)}$. The mechanisms underlying these protein-induced satiety effects, involving different and complex pathways that include both indirect vagus-mediated signals and the direct sensing of blood amino acids (AA), nutrients and hormones by specific brain areas, are not fully understood ${ }^{(5)}$.

The current thinking is that proteins are more efficient than fats $^{(6)}$ or carbohydrates $(\mathrm{CHO})^{(7,8)}$ in inducing satiety. However, discrepancies have been observed between studies regarding the satiating capacity of proteins ${ }^{(9)}$, although these could be attributed to methodological conditions that hamper the interpretation of the results, such as the macronutrient content and other food parameters, texture ${ }^{(10)}$, structure, energy level or the time period elapsing between the preload and the test meal $^{(11)}$. This period is frequently fixed, and only a few studies have observed the satiety response in human subjects who were free to request the next meal at any time ${ }^{(12-14)}$. Subjects may also differ in their ability to sense nutrient and energy intakes and adapt their overall food intake accordingly, which may particularly be the case in overweight subjects or obese as opposed to lean subjects ${ }^{(15,16)}$. Lastly, different protein sources have also been suspected of differently influencing the induction of satiety, with contrasting results ${ }^{(1,2,17,18)}$. Particularly, the satiating effect of whey protein and casein in relation to their digestive kinetics and

Abbreviations: AA, amino acids; CAS, casein; CHO, carbohydrates; GIP, glucose-dependent insulinotropic peptide; GLP-1, glucagon-like peptide 1; HNRC, Human Nutrition Research Centre; MIX, equal mix of casein and whey protein; WP, whey protein.

*Corresponding author: Dr C. Gaudichon, fax +331440818 58, email claire.gaudichon@agroparistech.fr 
subsequent postprandial changes in plasma AA and hormones has been extensively addressed but remains controversial ${ }^{(3,19,20)}$. The direct link between satiety responses to milk protein fractions and their digestion rate can, however, be hardly challenged in a unique protocol due to the problems inherent in obtaining access to the gastrointestinal tract.

The present study was designed to assess whether the type of milk protein fractions, particularly differing in terms of their digestion kinetics, could modulate the satiating effect of a protein load in overweight subjects. For this purpose, the satiating effect of three different protein snacks (casein, whey protein or a 50:50 mixture of the two) was assessed in each subject against a basal CHO load, especially on the basis of the duration of satiety. Digestive kinetics and subsequent postprandial changes in plasma AA induced by different milk proteins were determined using a ${ }^{15} \mathrm{~N}$-labelled meal test in a subgroup of subjects equipped with a jejunal tube.

\section{Materials and methods}

\section{Participants and study design}

All participants were certified to be in good health after a thorough physical examination performed by medical staff in the Human Nutrition Research Centre (HNRC) at Avicenne Hospital (Bobigny, France), as well as routine biochemical tests. The inclusion criteria were $25<\mathrm{BMI}<30 \mathrm{~kg} / \mathrm{m}^{2}$ and $18<$ age $<40$ years. The exclusion criteria were positive serology for HIV, hepatitis B and C virus, any pathology, allergy to dairy proteins, pregnancy or an absence of contraception in women. The purpose and potential risks of the study were fully explained to the subjects. The study was conducted accorded to the guidelines laid down in the Declaration of Helsinki, and all procedures involving human subjects were approved by the Ethics Committee of Saint-Germain-en-Laye Hospital. Written informed consent was obtained from all participants. The study was registered at www.ClinicalTrials.gov (NCT00862329, SURPROL). It was performed in the HNRC at Avicenne Hospital under single-blind conditions according to a three-arm parallel design.

Subjects were recruited between March 2008 and June 2010, and recruitment was halted when the groups contained at least twenty-five subjects, including eight subjects for a digestive and metabolic investigation. Finally, eighty-two healthy overweight subjects took part in the study: thirty-eight females and forty-four males, with a mean BMI of 28 (SD 1.8) kg/m² and a mean age of 29 (SD 7) years. The subjects were allocated by the data manager to one of three groups ( $n$ 26-28 per group): casein (CAS group); whey protein (WP group); a 50:50 mix of the two (MIX group). During the final third of the study, BMI, age and sex were used to homogenise the groups. Sex ratio, weight, BMI and BMR values did not differ between the groups (Table 1).

\section{Protocol}

For satiety, each subject completed a control (snack without protein) and treatment (snack with protein) test. The subjects
Table 1. Characteristics of the study subjects

(Mean values and standard deviations)

\begin{tabular}{|c|c|c|c|c|c|c|}
\hline & \multicolumn{2}{|c|}{ CAS group } & \multicolumn{2}{|c|}{ WP group } & \multicolumn{2}{|c|}{ MIX group } \\
\hline & Mean & SD & Mean & SD & Mean & SD \\
\hline \multicolumn{7}{|l|}{$\operatorname{Sex}(n)$} \\
\hline Female & \multirow{2}{*}{\multicolumn{2}{|c|}{$\begin{array}{l}15 \\
13\end{array}$}} & \multicolumn{2}{|c|}{15} & \multicolumn{2}{|c|}{12} \\
\hline Male & & & \multicolumn{2}{|c|}{11} & \multicolumn{2}{|c|}{16} \\
\hline Weight (kg) & 82.6 & 11.4 & 83.1 & 9.4 & 82.9 & 8.8 \\
\hline BMI $\left(\mathrm{kg} / \mathrm{m}^{2}\right)$ & $28 \cdot 1$ & 1.9 & 27.9 & $1 \cdot 7$ & 28.2 & $2 \cdot 0$ \\
\hline Age (years) & $28 \cdot 8$ & 7.5 & $28 \cdot 3$ & $6 \cdot 9$ & $28 \cdot 8$ & 7.4 \\
\hline $\mathrm{BMR}^{\star}(\mathrm{MJ})$ & $7 \cdot 3$ & $1 \cdot 1$ & 7.5 & $1 \cdot 0$ & 7.4 & 0.9 \\
\hline
\end{tabular}

CAS, casein; WP, whey protein; MIX, equal mix of casein and whey protein.

${ }^{*}$ BMR was calculated from the equations of Harris and Benedict.

were thus their own controls (Fig. 1). A subgroup of twentyfour subjects underwent a digestive and metabolic test after ingesting the protein snack ( $n 8$ per group).

Satiety assessment. On day 1, the subjects underwent a control satiety test. They visited the HNRC in the morning after an overnight fast. The subjects were placed in a room with no time cues (closed curtains and no television, watch or personal computer). They were allowed to read and listen to pre-recorded music. They were given a standardised breakfast $(1170 \mathrm{~kJ})$ at 08.00 hours, including $120 \mathrm{ml}$ skimmed milk, $30 \mathrm{~g}$ cornflakes, $100 \mathrm{ml}$ orange juice, $20 \mathrm{~g}$ sugar, and tea or coffee, which they had to ingest in $30 \mathrm{~min}$. At 11.00 hours, they had to ingest in $15 \mathrm{~min}$ a liquid control snack $(1003 \mathrm{~kJ})$ composed of $60 \mathrm{~g}$ maltodextrin (Roquette). The snack was dissolved in water to reach a final volume of $500 \mathrm{ml}$ and flavoured with orange. After the control snack, the subjects were asked to request for lunch when they felt hungry. The meal proposed contained an excess quantity of food, including pasta, tomato sauce, cottage cheese, fruit salad and water. The time period elapsing between the snack and the spontaneous meal request was recorded, as was the energy intake at lunch. Regularly throughout the satiety test, the subjects completed visual analogue scales to evaluate their appetite feelings.

After the control test, volunteers returned home and were asked to consume every morning one liquid protein snack for $5 \mathrm{~d}$. The protein snacks were isoenergetic with the control snack and composed of $30 \mathrm{~g}$ maltodextrin, and $30 \mathrm{~g}$ casein, whey protein or mix $(1003 \mathrm{~kJ})$. Proteins were purchased from Ingredia. The subjects were given five shakes containing the protein load powder and orange flavour for selfadministration after its dissolution in $500 \mathrm{ml}$ water. The nature of the protein load was not revealed to the subjects in respect of the single-blind design.

On day 7, the subjects came back to the HNRC for the same satiety test as on day 1 , but with the protein snack. The satiating power of the protein snack was assessed in each subject as against the control snack. Satiety parameters were thus the main outcome of the study.

Digestive and metabolic measurements. On day 8 , a subgroup of twenty-four subjects ( $n 8$ per group) was used to investigate digestive, hormonal and metabolic parameters that might be associated with satiety. They were equipped 


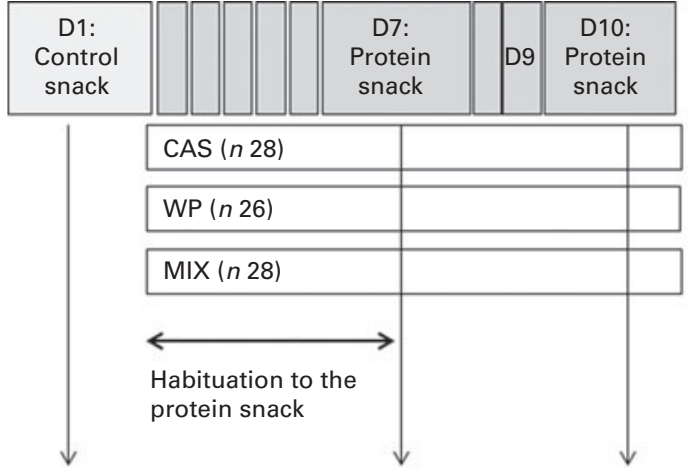

Satiety test

Satiety test

Digestive exploration

Satiety $(n 82)$

Digestion ( $n$ 24)

Fig. 1. Experimental design. Eighty-two subjects, divided into three groups (casein (CAS), whey protein (WP) and an equal mix of the two (MIX)), followed two satiety tests after ingestion of a control snack (without protein) on day 1 (D1) and a protein snack on day 7 (D7). A subgroup of twenty-four subjects underwent a digestive and metabolic exploration after ingesting the protein snack on day 10 (D10).

with a double-lumen nasogastric tube that migrated to the proximal jejunum, as described previously ${ }^{(21,22)}$. The location of the sampling site was controlled by radiography. On day 9 , after the subjects had fasted overnight, a solution of polyethylene glycol (PEG)-4000, used as a non-absorbable marker, was infused through the intestinal tube. After the baseline sampling of jejunal effluents and plasma, the subjects ingested their liquid protein snack in the same way as during the control satiety test, but in this case the proteins were intrinsically labelled with ${ }^{15} \mathrm{~N}$, as described previously ${ }^{(23)}$. Intestinal effluents were collected continuously on ice for $6 \mathrm{~h}$ after the snack, and blood samples were collected every $30 \mathrm{~min}$ for $3 \mathrm{~h}$ and hourly thereafter. The subjects were given $80 \mathrm{ml}$ water every hour. At the end of this test period, the gastrointestinal tube was removed and the subjects returned home after eating a complete meal.

\section{Analyses}

Effluents were pooled into $30 \mathrm{~min}$ periods and freeze-dried until analysis. The concentration of PEG- 4000 in digesta samples was measured using a turbidimetric method, as described previously $^{(24)}$, to determine the liquid flow rate. Enrichment of total $\mathrm{N}$ and ${ }^{15} \mathrm{~N}$ was determined by the elemental analysisisotope ratio MS method, as described previously ${ }^{(25)}$.

Plasma AA were analysed by ion-exchange chromatography after protein precipitation, with the addition of norleucine as an internal standard (Biotech Instrument). The ${ }^{15} \mathrm{~N}$ enrichment of AA was determined by isotope ratio MS (IsoPrime, GV Instrument) coupled to an elemental analyser (Euro Elemental Analyser 3000; EuroVector), after purification on Dowex AG-50 X8 resin, as described previously ${ }^{(23,26)}$. The dietary $\mathrm{N}$ level in plasma AA was calculated as follows:

$\operatorname{Dietary} \mathrm{AA}(\mathrm{mmol})=\mathrm{N}_{\text {plasma AA }}(\mathrm{mmol} / \mathrm{l}) \times \mathrm{APE}_{\text {sample }} / \mathrm{APE}_{\text {meal }}$, where $\mathrm{N}_{\text {plasma AA }}$ was calculated from the sum of $\mathrm{N}$ in individual plasma AA (on the basis of concentrations) and the estimated volume of plasma as $5 \%$ of body weight ${ }^{(27)}$. $\mathrm{APE}_{\text {sample }}$ and $\mathrm{APE}_{\text {meal }}$ are the ${ }^{15} \mathrm{~N}$ enrichment in the digesta and meal, respectively, where APE stands for atom percentage excess.

Concentrations of plasma insulin, glucagon, glucosedependent insulinotropic peptide (GIP), glucagon-like peptide 1 (GLP-1), peptide YY and ghrelin (active form) were analysed using a human endocrine panel (Milliplex Millipore) on a Bioplex 200 system (Bio-Rad Laboratories, Inc.). The intra-assay CV ranged from $5.5 \%$ for GLP-1, insulin and peptide $\mathrm{YY}$ to $10 \%$ for glucagon. The inter-assay $\mathrm{CV}$ ranged from $6.5 \%$ for GIP to $23 \%$ for GLP-1.

\section{Statistical analyses}

Data are presented as means with their standard errors. The number of subjects necessary to recruit was calculated from a power test based on the time period elapsing between the snack and request for lunch, using the software GPower 3.1. Only a few data were available in the literature to draw hypothesis on the differences between a $\mathrm{CHO}$ and protein snack, depending on the type of protein. In the study of Marmonier et $a l .{ }^{(28)}$, the time period elapsing between the snack and meal request was $471 \mathrm{~min}$ after a $\mathrm{CHO}$ snack $v .429 \mathrm{~min}$ after a high-protein snack, associated with a within standard deviation of $30 \mathrm{~min}$. We targeted differential effects of $10 \mathrm{~min}$ between two groups with a standard deviation of 25 , resulting in an effect size of 0.35 . It was then calculated that at least eighty subjects needed to be enrolled to ensure a statistical power of $80 \%$ and thus to detect differences between the three groups using a one-way ANOVA, with an $\alpha$ level of $5 \%$.

The effect of qualitative (group and sex) and quantitative (BMI, weight, BMR and values of the control snack) variables on satiety parameters was also tested within ANOVA or ANCOVA models, using the generalised linear model procedure of SAS.

Changes in visual analogue scales after the snack were compared between the control and protein snacks using a mixed model with two repeated factors, time and test (PROC MIXED, SAS 9.1). The effects of the protein snack on digestive kinetics and hormones were compared between groups using a mixed model, with time as the repeated factor and BMR as a covariate, to take into account the fact that the amount of the snack was similar among subjects. $P \leq 0.05$ was taken as the criterion for statistical significance.

\section{Results}

\section{Digestion kinetics}

Flow rates of dietary $\mathrm{N}$ in the jejunum (Fig. 2(a)) differed significantly as a function of group, with a substantial delivery during the first $3 \mathrm{~h}$ after ingesting whey protein or mix while casein was delivered progressively in two phases during the first $3 \mathrm{~h}$ and between 4 and $5 \mathrm{~h}$. The rate of appearance of dietary AA in plasma (Fig. 2(b)) reflected the rapid and slow gastric emptying of whey protein and casein, respectively, 


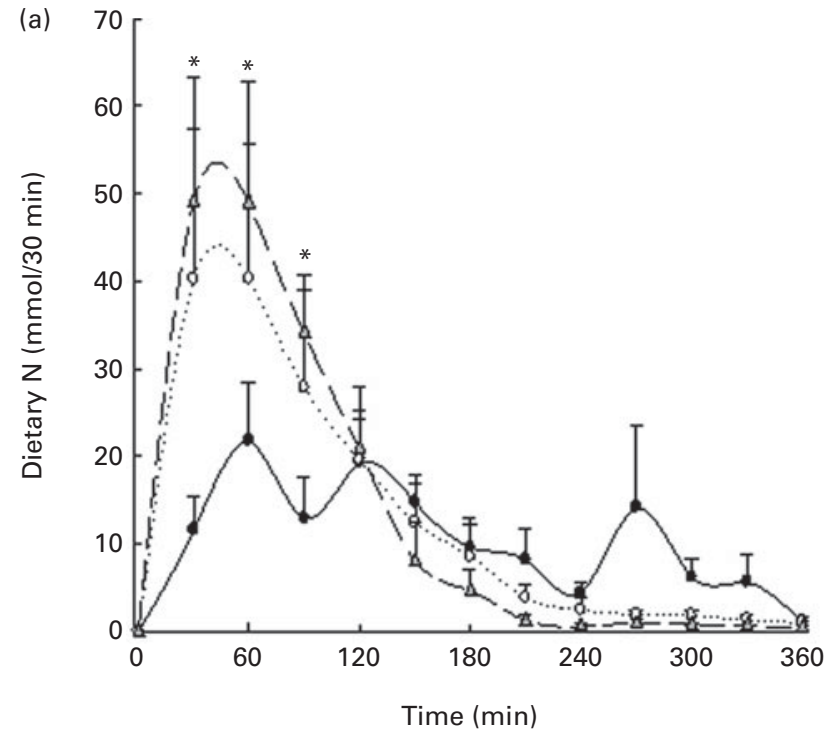

(b)

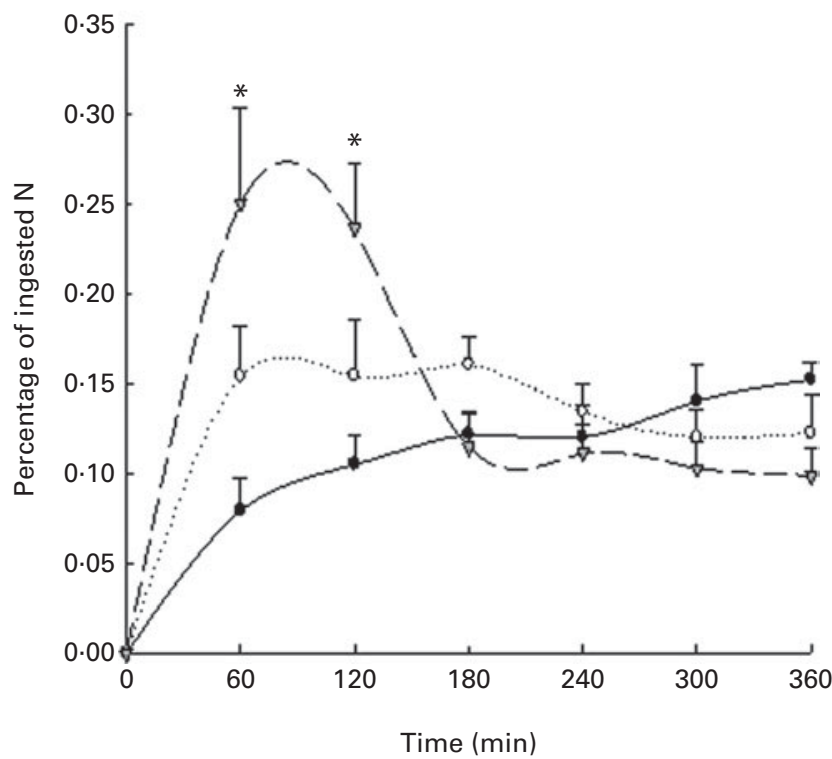

Fig. 2. Flow rates of dietary nitrogen in the jejunum (a) and dietary amino acid appearance in the plasma (b) in a subgroup of twenty-four subjects, after ingestion of a protein snack containing ${ }^{15} \mathrm{~N}$-labelled milk proteins (casein $(--)$, whey protein $\left(-\Delta_{-}\right)$and an equal mix of the two $(\cdots-\cdots)$ ). Values are means $(n 8$ per group), with their standard errors represented by vertical bars. * Time point at which a group effect was observed $(P<0.05)$. The effects of group, time and interaction were tested in a mixed model with time as a repeated factor. There were significant effects observed for time $(P<0.0001$, for both (a) and (b)) and the time $\times$ group interaction ((a) $P=0.001$ and (b) $P=0.006$ ).

with an intermediate value for the mix of the two. Indeed, the casein snack did not trigger any peak for dietary AA but a progressive rise throughout the $6 \mathrm{~h}$, whereas whey protein resulted in a massive appearance within $3 \mathrm{~h}$. After the mix snack, a maximal appearance of dietary AA was observed as soon as $1 \mathrm{~h}$ and was followed by a plateau.

Levels of gastrointestinal and pancreatic hormones were also determined (see Fig. S1, available online). The secretion of insulin and GIP in response to the ingestion of the protein snack was similar in the three groups, with a peak at $0.5 \mathrm{~h}$ to reach approximately $300 \mathrm{pmol} / \mathrm{l}$ and a return to the baseline at 3 h. Peptide YY, glucagon and GLP1 did not vary significantly over time while ghrelin levels gradually rose during the investigation. A trend for a group effect $(P=0 \cdot 06)$ was obtained with GLP-1, with a globally lower secretion in the CAS group than in the other two groups.

\section{Influence of snacks on satiety}

Post-snack feelings of hunger (Fig. 3(a)) and fullness (Fig. 3(b)) did not differ between the groups (mixed model with time and snack as repeated factors). There was also no significant difference between the control and protein snacks.

The time period elapsing between the control $\mathrm{CHO}$ snack and request for lunch was 133 (SEM 7) min (median $126 \mathrm{~min}$, range $15-385 \mathrm{~min}$ ). The time period elapsing after the protein
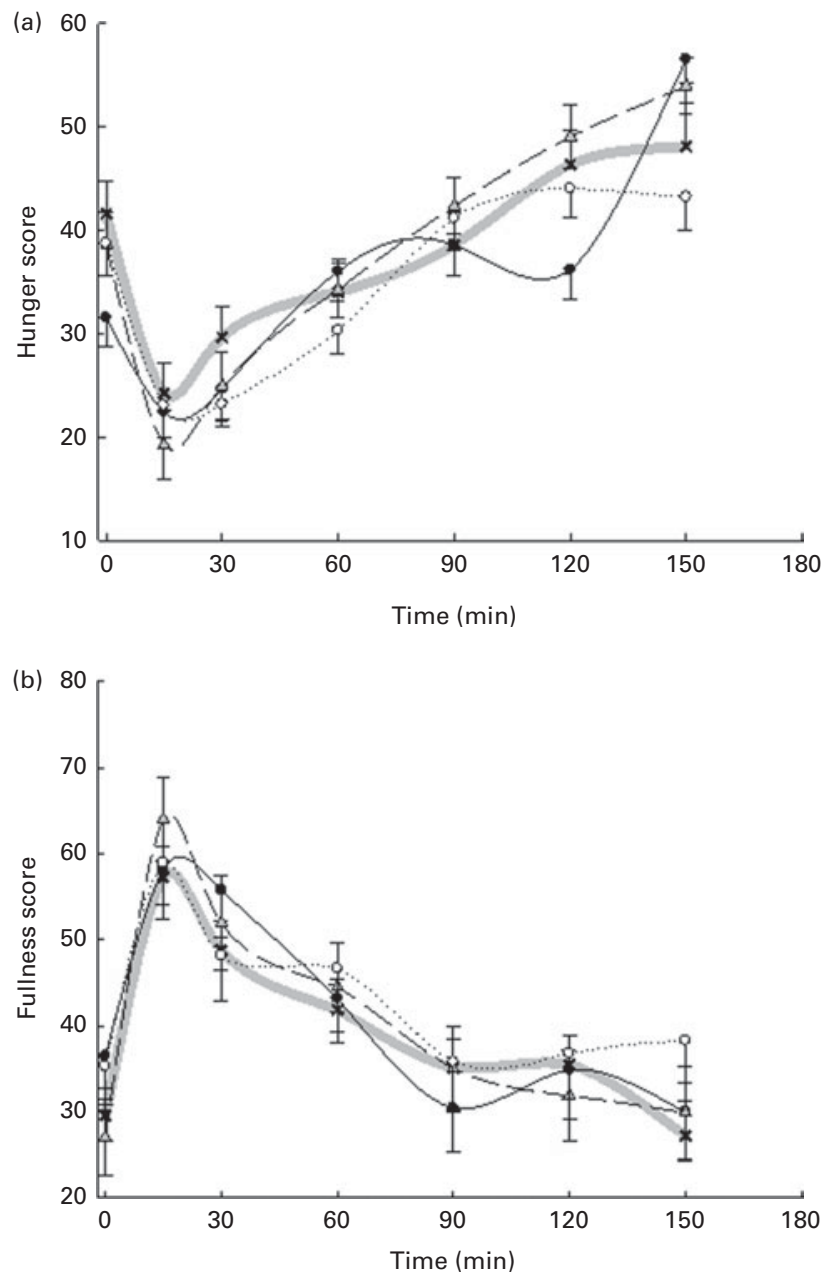

Fig. 3. Feelings of hunger (a) and fullness (b) after ingestion of the control ( $n$ 82) or protein ( $n$ 26-28 per group) snack. The snack was given at $t=0 \mathrm{~min}$. Values are means, with their standard errors represented by vertical bars. There was no significant effect observed for snack (protein $v$. control $\left(\Sigma_{-}\right)$) or the type of protein snack (casein $(-\bullet-)$, whey protein $(-\triangle-)$ and an equal mix of the two (.....); mixed model with protein as a factor and time as a repeated factor). 
snack, whatever the type of protein, was 150 (SEM 7.5) min (median $150 \mathrm{~min}$, range $15-345 \mathrm{~min}$ ). As a result, the protein snack significantly increased this period by 17 (SEM 7) min compared with the control snack $(P=0.02)$. There was no significant effect of group (CAS, MIX or WP) on either the time period elapsing after the protein snack or the difference from the values obtained after the control snack, as shown in Fig. 4(a). Besides, the time period elapsing after the protein snack was significantly dependent on the time period elapsing after the control snack (ANCOVA, $P<0 \cdot 0001$ ), indicating that the duration of satiety was strongly subject-dependent.
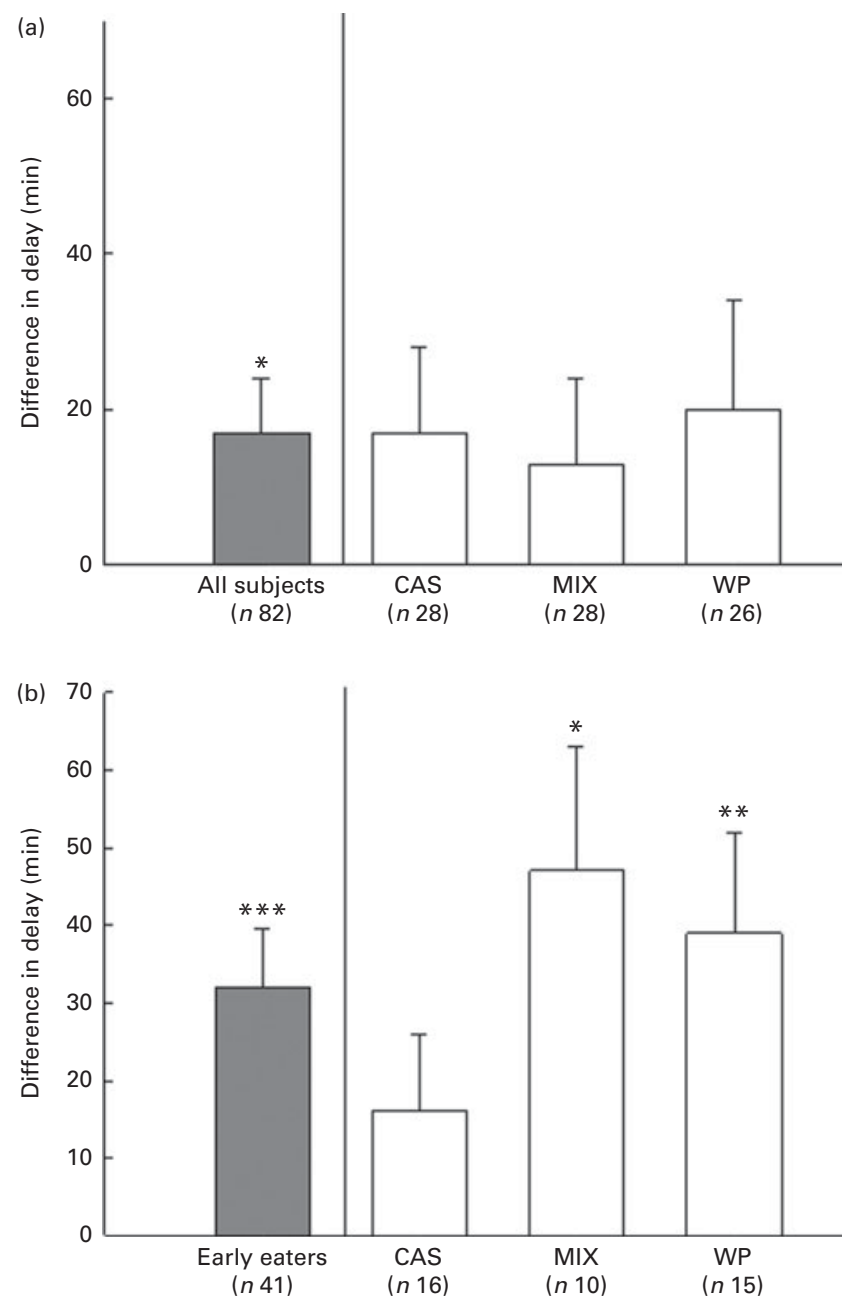

Fig. 4. Effects of the protein snack $v$. the control carbohydrate snack on the time period elapsing before the request for lunch in all subjects $(n$ 82) (a) and in early eaters $(n$ 41) (b). The satiating effect of the protein snack is represented whatever the type of protein snack as well as in each protein group (intention-to-treat, $n$ 26-28; early eaters, $n$ 10-16). Data are expressed as the difference between the values obtained after ingestion of the protein snack and the control snack, respectively. Early and late eaters were split on the basis of the time period elapsing after ingesting the control snack (cut-off point: median $126 \mathrm{~min}$ ). Values are means, with their standard errors represented by vertical bars. Mean value was significantly different from $0 \mathrm{~min}$ : ${ }^{\star} P \leq 0.05,{ }^{* \star} P \leq 0.01,{ }^{\star \star *} P \leq 0.001$. There was no effect observed for the protein group (ANOVA with group as a factor). CAS, casein; MIX, equal mix of casein and whey protein; WP, whey protein.
In contrast, there was no effect of subject-related variables such as sex, body weight, BMI or BMR.

Owing to the significant relationship between the control test and the satiety response to the protein snack, a split analysis was performed in subjects displaying an initially short time period (early eaters) or long time period (late eaters) for meal request after the control snack (cut-off point: median $126 \mathrm{~min}$ ). In early eaters, the time period for lunch request after the protein snack was increased by 32.4 (SEM 7.5) min $(P=0.0001)$, whereas in late eaters, the protein snack did not have any effect. Although the ANOVA did not reveal any significant effect of the type of protein snack on the delay in this subgroup of subjects (Fig. 4(b)), the extension of the duration of satiety compared with the control snack was only significant in the WP and MIX groups, but not in the CAS group.

Energy intake at lunch was $4 \cdot 2($ SEM $0 \cdot 1)$ MJ after the control snack (median $4 \cdot 1 \mathrm{MJ}$, range $1 \cdot 8-6 \cdot 5 \mathrm{MJ}$ ). After the protein snack, energy intake at lunch was $4 \cdot 2$ (SEM 1.3) MJ and did not differ compared with the control snack. Energy intake after the protein snack was not influenced by the type of protein but by the energy intake at the control test (ANCOVA, $P<0.0001$ ). In contrast to the time period elapsing between the snack and request for lunch, subject-related variables influenced energy intake at lunch, such as sex $(P=0 \cdot 0005)$ and BMR $(P=0 \cdot 0007)$. Baseline energy intake was also positively linked to weight $(R 0.027, P=0.01)$ but not to BMI. Energy intake at lunch was not influenced by the length of time after the control snack.

\section{Discussion}

The present study addressed the sensitivity of overweight subjects to the satiating effect of different milk protein snacks, differing in terms of protein type and consequently digestive kinetics. Milk proteins, whatever their type, moderately but significantly extended the appetite-suppressant effect of a liquid $\mathrm{CHO}$ snack. A post hoc analysis revealed that the satiating effect of proteins were only efficient in subjects displaying a short duration of satiety. The absence of any effect of milk protein fractions despite the marked difference in their digestion kinetics indicates that in our experimental conditions, the modulation of the kinetics of dietary AA delivery did not influence the duration of satiety.

Although kinetic profiles were modulated between the three different protein snacks, displaying marked differences in the rate of appearance of dietary AA in plasma, there was no difference between the protein sources in relation to the effect on the duration of satiety. This modulation was characterised in a subgroup of subjects, but not at the same time as the satiety test, because the presence of the intestinal tube was not compatible with assessing satiety. At the jejunal level, the half delivery time of dietary $\mathrm{N}$ was $50 \mathrm{~min}$ with whey protein and $2 \mathrm{~h}$ with casein, but with an estimated complete emptying time (based on cumulated recovery) of $2.5 \mathrm{~h}$ with whey protein and $6 \mathrm{~h}$ with casein. The mix snack displayed similar kinetics to that for whey protein (half delivery time of $1 \mathrm{~h}$ ) but with an estimated complete digestion time of $4 \mathrm{~h}$. The appearance of ${ }^{15} \mathrm{~N}$ in plasma AA provided a good 
discrimination of kinetics, with a peak time at 90 min for whey protein and the absence of a peak for casein, while the mix of the two displayed an early maximum ( $1 \mathrm{~h}$ ) followed by a plateau. These digestive and plasma AA kinetic profiles are in agreement with those observed previously ${ }^{(23,29,30)}$, with the peculiarity that due to clotted aggregates in the stomach, casein did not trigger a plasma AA peak. We were thus able to verify that mixing casein and whey protein in equal proportion produced an intermediate kinetic.

Despite these differences, there were no effects on appetite rating. Several studies have compared the satiating effects of different milk proteins, of which the most widely studied are whey protein and casein or total milk proteins. However, the results of the studies reported to date have been contradictory. Some authors have found a stronger effect of whey $\operatorname{protein}^{(3)}$, casein $^{(31)}$ or total milk proteins ${ }^{(19)}$, or no difference ${ }^{(2)}$. This latter study was performed in overweight women in order to compare liquid preloads (milk shake, $1 \cdot 1 \mathrm{MJ}$ ) containing $50 \mathrm{~g}$ whey protein, soya, gluten or glucose. Energy intake during a subsequent buffet meal was lower by $10 \% 3 \mathrm{~h}$ after ingesting all the protein preloads when compared with the glucose treatment, but without there being any differences between the protein sources. It should be noted that unlike the present experiment, all these studies implemented a fixed period between the load and the meal. Interestingly, in young men, a modification to food texture by increasing the viscosity of a liquid casein snack using transglutaminase increased fullness compared with a liquid casein or whey protein snack, but decreased the secretion of GLP-1 and cholecystokinin ${ }^{(20)}$. In the present study, no differences between casein and whey protein were observed, although the total gastric emptying time after ingestion of the casein snack was delayed by about $4 \mathrm{~h}$. This could suggest that an excessive slowing of digestive kinetics, together with a high-protein dose $(50 \mathrm{~g})$, is necessary to obtain an effect on the duration of satiety. Furthermore, it shows that higher peaks of plasma GLP-1 and cholecystokinin observed during the early postprandial phase are not necessarily linked to a stronger satiating effect.

We also did not find any marked effects of the type of protein snack on hormonal profiles. A high variability was observed, especially for gastrointestinal hormones, which may have been partly due to the presence of the intestinal tube and to the fact that the energy load of the snack was unique whatever the corpulence of the subjects, resulting in the contribution of 10 to $17 \%$ to the BMR, although without any differences between the protein groups. Insulin and GIP were principally triggered by the presence of maltodextrin $(30 \mathrm{~g})$ in the snack, buffering the insulinotropic capacity of whey protein ${ }^{(32)}$. The only effect on GLP-1 was global, without affecting the kinetics, with a lower level in the CAS group. The absence of difference between casein and whey protein is in line with most previous findings ${ }^{(2,20,33)}$, but not all $^{(3)}$. However, all these studies were performed with $50 \mathrm{~g}$ protein without $\mathrm{CHO}$, whereas the present study used a dose more compatible with a supplementation strategy, meaning $30 \mathrm{~g}$. At a lower dose $(15 \mathrm{~g})$, higher levels of GLP-1 and cholecystokinin secretion have been reported after ingestion of total milk proteins than that of whey $\operatorname{protein}^{(34)}$
The present study also addressed the effect of the protein snack against the $\mathrm{CHO}$ snack, and particularly in relation to the duration of satiety, a parameter that has been scarcely assessed. In one study, an increase in time period elapsing after a high-protein load compared with a high-CHO load ${ }^{(28)}$ has been reported; however, most of the investigations were performed with a fixed time interval between the load and the meal. We found that the duration of the satiating effect was increased by approximately $17 \mathrm{~min}$ when the snack contained proteins, in comparison to an isovolumic and isoenergetic (1 MJ) snack containing maltodextrin. The result of the present study is consistent with that of Douglas et al. ${ }^{(14)}$ who found an increase in the duration of satiety from $150 \mathrm{~min}$ with a low-protein yogurt to $180 \mathrm{~min}$ with a highprotein one. In contrast, there was no effect on energy intake at lunch. This illustrates the fact that because the period was not fixed and subjects received their lunch when they were hungry, this criterion was no longer discriminating. Chungchunlam et al. ${ }^{(35)}$ did not find a significant effect of the timing of the preload varying from 30 to $120 \mathrm{~min}$ on energy intake; however, this does not preclude the fact that after $120 \mathrm{~min}$, the effect of the preload altered the result. Moreover, by contrast, with the time period elapsing after the snack, we found that energy intake was influenced by sex, as shown previously $^{(18)}$, and also by BMI and BMR, thus increasing the factors influencing this criterion. Therefore, under the present experimental conditions, energy intake at meal was not a sensitive criterion, while the time period elapsing was the most appropriate one. As stated by Blundell et al. ${ }^{(11)}$, the period during which a preload maintains a state of satiety can be considered as a good indicator to assess its satiety power. Interestingly, we found that the periods obtained after the protein snack varied considerably (15-385 min) and were strongly dependent on the periods observed following the control snack. We thus reanalysed the results after splitting the subjects as early and late eaters, and found that the duration of the satiating effect of proteins was extended by $32 \mathrm{~min}$ in early eaters but not in late eaters. This shows that the efficacy of proteins in extending the duration of satiety depends on their sensitivity to an energy load. In subjects in whom a non-protein snack triggers a sufficient duration of satiety, proteins do not exert any additional benefit. Interestingly, it has recently been shown that the usual mealtime interval of subjects influences the extent to which they could lose weight during dietary intervention ${ }^{(36)}$.

This split was performed with two subgroups in order to retain sufficient statistical power to further test the effect of proteins. However, an analysis with three subgroups produced similar results, with a significant effect of proteins in early and medium eaters, and no effect in late eaters. The present study thus provides new insights that should be investigated specifically in further studies. Lastly, the split analysis suggests that the presence of whey protein could extend the duration of satiety in early eaters. Indeed, compared with the CHO snack, the satiating effect of proteins was only significant in the WP and MIX groups, but we were unable to find a group effect, probably due to a loss of statistical power subsequent to splitting. A specific study on subjects recruited for their ability 
to respond to an energy load would therefore be necessary to ascertain a higher satiating power of whey protein in subjects displaying a short duration of satiety.

The present study was performed using an original approach that could investigate in the same subjects both the jejunal flux of dietary protein and the satiety response to a snack. A second original approach was that the design of the present study first included a control satiety test, allowing the classification of subjects in the absence of any protein in the snack, and then a second test to determine the additional effect of proteins, after habituation to the snack. Because of this original approach, the present study had some limitations. In particular, a cross-over design could not be implemented, leading to a loss of statistical power for between-group analysis. Furthermore, we could not verify the effect of snack order. Lastly, although the subjects were habituated to the snack - a design that has been rarely employed in other studies - the habituation period remained short. It would be interesting to evaluate the effect of a longer adaptation period and its subsequent impact on food consumption and weight. To our knowledge, very few studies have assessed this long-term effect. A sustainable effect on hunger feelings has been reported in subjects regularly consuming a satiating snack for 18 weeks after weight loss, together with better weight maintenance ${ }^{(37)}$; however, this result cannot be generalised. The present study focused on the duration of satiety and did not allow for any speculation regarding its possible effects on food intake.

In conclusion, the kinetics of dietary AA delivery do not play a major role in satiety responses. The present results also show that the effect of proteins in inducing satiety needs to be interpreted in terms of target subjects, particularly relative to their sensitivity to satiety. The variability in the duration of satiety was extremely high among individuals, as has already been shown for daily energy intake between individuals of the same sex, age, body composition and activity levels ${ }^{(38)}$, and we showed that proteins were efficient when compared with $\mathrm{CHO}$ alone in early eaters. To our knowledge, this is the first study to demonstrate that sensitivity to satiety (short or long satiety period) influences the effect of specific macronutrients on satiety responses. Such new criteria could be taken into account when using loads enriched with macronutrients for the control of energy intake.

\section{Supplementary material}

To view supplementary material for this article, please visit http://dx.doi.org/10.1017/S0007114514001470

\section{Acknowledgements}

The authors thank Marie Claude Amar from the Volunteer Research Center at Avicenne Hospital for recruiting the subjects and collecting the samples, as well as Laure Chevalier and Cécile Bos for their active participation in the study.

The authors are indebted to the Corrine Marmonier and Jean-Pierre Guyonnet, from the CNIEL, for constructive scientific discussions.
The present study was supported by a grant from the CNIEL and the French Agency for Research and Technology (Program PNRA 2006; SURPROL). The authors are participants of the EU-funded COST action INFOGEST (COST FA 1005).

The authors' contributions are as follows: A. M.-B. and C. G. designed the research; A. M.-B., C. G., G. A., C. P., J. P., R. B. and D. R. conducted the research; J. L. supplied the labelled milk proteins; C. G., A. M.-B. and C. P. analysed the data; A. M.-B., C. G., G. F. and D. T. wrote the paper; A. M.-B. and C. G. had primary responsibility for the final content. All authors read and approved the final version of the paper.

The authors declare that there are no conflicts of interest.

\section{References}

1. Anderson GH, Tecimer SN, Shah D, et al. (2004) Protein source, quantity, and time of consumption determine the effect of proteins on short-term food intake in young men. J Nutr 134, 3011-3015.

2. Bowen J, Noakes M \& Clifton PM (2006) Appetite regulatory hormone responses to various dietary proteins differ by body mass index status despite similar reductions in ad libitum energy intake. J Clin Endocrinol Metab 91, 2913-2919.

3. Hall WL, Millward DJ, Long SJ, et al. (2003) Casein and whey exert different effects on plasma amino acid profiles, gastrointestinal hormone secretion and appetite. Br J Nutr 89, 239-248.

4. Westerterp-Plantenga MS, Nieuwenhuizen A, Tome D, et al. (2009) Dietary protein, weight loss, and weight maintenance. Annu Rev Nutr 29, 21-41.

5. Fromentin G, Darcel N, Chaumontet C, et al. (2012) Peripheral and central mechanisms involved in the control of food intake by dietary amino acids and proteins. Nutr Res Rev $\mathbf{2 5}$, 29-39.

6. Porrini M, Santangelo A, Crovetti R, et al. (1997) Weight, protein, fat, and timing of preloads affect food intake. Physiol Behav 62, 563-570.

7. Bertenshaw EJ, Lluch A \& Yeomans MR (2008) Satiating effects of protein but not carbohydrate consumed in a between-meal beverage context. Physiol Behav 93, 427-436.

8. Poppitt SD, McCormack D \& Buffenstein R (1998) Short-term effects of macronutrient preloads on appetite and energy intake in lean women. Physiol Behav 64, 279-285.

9. Raben A, Agerholm-Larsen L, Flint A, et al. (2003) Meals with similar energy densities but rich in protein, fat, carbohydrate, or alcohol have different effects on energy expenditure and substrate metabolism but not on appetite and energy intake. Am J Clin Nutr 77, 91-100.

10. Wanders AJ, Mars M, Borgonjen-van den Berg $\mathrm{KJ}$, et al. (2014) Satiety and energy intake after single and repeated exposure to gel-forming dietary fiber: post-ingestive effects. Int J Obes (Lond) 38, 794-800.

11. Blundell J, de Graaf C, Hulshof T, et al. (2010) Appetite control: methodological aspects of the evaluation of foods. Obes Rev 11, 251-270.

12. Chapelot D \& Payen F (2010) Comparison of the effects of a liquid yogurt and chocolate bars on satiety: a multidimensional approach. BrJ Nutr 103, 760-767.

13. Marmonier C, Chapelot D \& Louis-Sylvestre J (2000) Effects of macronutrient content and energy density of snacks consumed in a satiety state on the onset of the next meal. Appetite 34, 161-168. 
14. Douglas SM, Ortinau LC, Hoertel HA, et al. (2013) Low, moderate, or high protein yogurt snacks on appetite control and subsequent eating in healthy women. Appetite 60, 117-122.

15. Brennan IM, Luscombe-Marsh ND, Seimon RV, et al. (2012) Effects of fat, protein, and carbohydrate and protein load on appetite, plasma cholecystokinin, peptide YY, and ghrelin, and energy intake in lean and obese men. $A m J$ Physiol Gastrointest Liver Physiol 303, G129-G140.

16. Ho A, Kennedy J \& Dimitropoulos A (2012) Neural correlates to food-related behavior in normal-weight and overweight/ obese participants. PLOS ONE 7, e45403.

17. Lang V, Bellisle F, Oppert JM, et al. (1998) Satiating effect of proteins in healthy subjects: a comparison of egg albumin, casein, gelatin, soy protein, pea protein, and wheat gluten. Am J Clin Nutr 67, 1197-1204.

18. Lam SM, Moughan PJ, Awati A, et al. (2009) The influence of whey protein and glycomacropeptide on satiety in adult humans. Physiol Behav 96, 162-168.

19. Lorenzen J, Frederiksen R, Hoppe C, et al. (2012) The effect of milk proteins on appetite regulation and diet-induced thermogenesis. Eur J Clin Nutr 66, 622-627.

20. Juvonen KR, Karhunen LJ, Vuori E, et al. (2011) Structure modification of a milk protein-based model food affects postprandial intestinal peptide release and fullness in healthy young men. Br J Nutr 106, 1890-1898.

21. Bos C, Airinei G, Mariotti F, et al. (2007) The poor digestibility of rapeseed protein is balanced by its very high metabolic utilization in humans. J Nutr 137, 594-600.

22. Bos C, Juillet B, Fouillet H, et al. (2005) Postprandial metabolic utilization of wheat protein in humans. $A m J$ Clin Nutr 81, 87-94

23. Lacroix M, Bos C, Leonil J, et al. (2006) Compared with casein or total milk protein, digestion of milk soluble proteins is too rapid to sustain the anabolic postprandial amino acid requirement. Am J Clin Nutr 84, 1070-1079.

24. Hyden S (1955) A turbidimetric method for the determination of higher polyethylene glycol in biological materials. Kungl Lantbbrukshogskolans Annaler 22, 139-145.

25. Boutrou R, Gaudichon C, Dupont D, et al. (2013) Sequential release of milk protein-derived bioactive peptides in the jejunum in healthy humans. Am J Clin Nutr 97, 1314-1323.

26. Airinei G, Gaudichon C, Bos C, et al. (2011) Postprandial protein metabolism but not a fecal test reveals protein malabsorption in patients with pancreatic exocrine insufficiency. Clin Nutr 30, 831-837.

27. Gannong W (1969) Review of Medical Physiology. Los Altos, CA: Lang Medical Publications.

28. Marmonier C, Chapelot D, Fantino M, et al. (2002) Snacks consumed in a nonhungry state have poor satiating efficiency: influence of snack composition on substrate utilization and hunger. Am J Clin Nutr 76, 518-528.

29. Boirie Y, Dangin M, Gachon P, et al. (1997) Slow and fast dietary proteins differently modulate postprandial protein accretion. Proc Natl Acad Sci U S A 94, 14930-14935.

30. Mahé S, Benamouzig R, Gaudichon C, et al. (1996) Nitrogen movements in the upper jejunum lumen in humans fed low amounts of caseins or $\beta$-lactoglobulin. Gastroenterol Clin Biol 19, 20-26.

31. Abou-Samra R, Keersmaekers L, Brienza D, et al. (2011) Effect of different protein sources on satiation and shortterm satiety when consumed as a starter. Nutr J 10, 139.

32. Calbet JA \& MacLean DA (2002) Plasma glucagon and insulin responses depend on the rate of appearance of amino acids after ingestion of different protein solutions in humans. J Nutr 132, 2174-2182.

33. Calbet JA \& Holst JJ (2004) Gastric emptying, gastric secretion and enterogastrone response after administration of milk proteins or their peptide hydrolysates in humans. Eur J Nutr 43, 127-139.

34. Diepvens K, Haberer D \& Westerterp-Plantenga M (2008) Different proteins and biopeptides differently affect satiety and anorexigenic/orexigenic hormones in healthy humans. Int J Obes (Lond) 32, 510-518.

35. Chungchunlam SM, Moughan PJ, Henare SJ, et al. (2012) Effect of time of consumption of preloads on measures of satiety in healthy normal weight women. Appetite 59, 281-288.

36. Garaulet M, Gomez-Abellan $\mathrm{P}$, Alburquerque-Bejar JJ, et al. (2013) Timing of food intake predicts weight loss effectiveness. Int J Obes (Lond) 37, 604-611.

37. Diepvens K, Soenen S, Steijns J, et al. (2007) Long-term effects of consumption of a novel fat emulsion in relation to body-weight management. Int J Obes (Lond) 31, 942-949.

38. George V, Tremblay A, Despres JP, et al. (1991) Further evidence for the presence of "small eaters" and "large eaters” among women. Am J Clin Nutr 53, 425-429. 